Journal of Nonformal Education and Community Empowerment

Volume 1 (2): 102-107, Desember 2017

Available at http://journal.unnes.ac.id/sju/index.php/jnfc

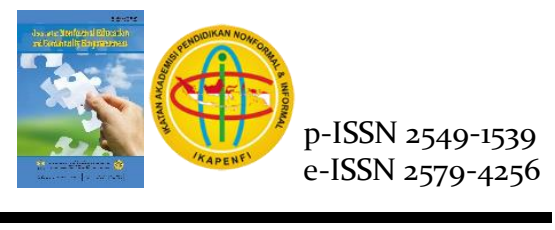

\title{
Pola Asuh Orangtua dalam Pendidikan Agama pada Remaja Muslim Minoritas di Amphoe Rattaphum Thailand
}

\author{
All Fine Loretha ${ }^{凶}$, Khomsun Nurhalim, U. Utsman \\ Pendidikan Luar Sekolah, Fakultas Ilmu Pendidikan, Universitas Negeri Semarang
}

DOI: $10.15294 /$ pls.v1i2.13319

\section{Info Artikel}

Sejarah Artikel:

Diterima Maret 2017

Disetujui Agustus 2017

Dipublikasikan Desember 2017

\section{Keywords:}

parenting; religious education; teenagers; moeslim minorities

\begin{abstract}
Abstrak
Penelitian ini bertujuan untuk mendeskripsikan pola asuh yang diterapkan orangtua, upaya-upaya yang dilakukan orangtua dan kendala-kendala yang dihadapi orangtua dalam keluarga muslim minoritas. Penelitian dilakukan di Amphoe Rattaphum Provinsi Songhkla Thailand dengan pendekatan kualitatif. Teknik Pengumpulan data dengan wawancara, observasi dan dokumentasi. Keabsahan data menggunakan teknik triangulasi sumber dan metode. Teknik analisis data melalui tahap reduksi data, penyajian data, dan penarikan kesimpulan. Hasil penelitian menunjukkan orangtua menerapkan pola asuh otoriter dan demokratis. Upaya-upaya yang dilakukan para orangtua dengan metode storytelling, suri tauladan, pembelajaran langsung, serta reward and punishment. Hambatan yang dihadapi orangtua meliputi kendala internal dan eksternal.
\end{abstract}

\begin{abstract}
This study aimed to describe parenting styles that applied by parents, the efforts that parents do to educate the adolescents and the constraints faced by parents in the family of the moeslim minority. The study was conducted in Amphoe Rattaphum Songhkla province of Thailand with a qualitative approach. The methods of observation, interview, and documentation. Validity methods by triangulation sources and methods. Data analysis techniques through of data reduction, data displays and conclusion. The results showed that parents apply authoritarian and democratic styles. The efforts by storytelling, role models, hands-on learning, as well as reward and punishment. Barriers faced by parents include internal and external factors.
\end{abstract}




\section{PENDAHULUAN}

Thailand merupakan salah satu negara yang berada di kawasan Asia Tenggara. Menurut Yusuf (2003:135), "Thailand adalah sebuah negara yang memiliki agama nasional yaitu Buddha. Agama ini memiliki persentase sebesar 94\% pemeluk agama yang tersebar di seluruh penjuru Thailand". Sejarah menunjukan sejak permulaan abad ke $13 \mathrm{M}$ terjadi penyebaran kedua agama Buddha ke wilayah Burma, Thailand, Kamboja, dan Tibet. Negara ini memiliki kekayaan kuil-kuil dan stupa-stupa Buddhis. Hampir di setiap wilayah Thailand, terdapat kuil atau klenteng tempat masyarakat beribadah. Dalam satu tambon terdapat sekitar 3 sampai 4 kuil yang dijadikan tempat ibadah masyarakat. Dewa yang disembahpun berbedabeda di setiap kuilnya. Bahkan peneliti sempat menemukan keluarga yang tiap anggotanya menyembah dewa yang berbeda. Selain itu, bendera nasional Thailand juga disebut simbol dari ajaran Buddha. Para biksu mendapatkan penghormatan tertinggi di Thailand dan orangorang mendorong keluarga mereka untuk bergabung masuk menjadi biksu.

Hanya sekitar 2,3 juta jiwa atau 5\% penduduk Thailand yang beragama Islam yang disebut dengan muslim minoritas. Menurut Aphornsuvan (2003:5), “Keluarga muslim adalah keluarga di negara Thailand yang beragama islam". Disebut keluarga muslim minoritas karena Islam adalah agama yang dianut oleh masarakat minoritas di negara Thailand. Kaum muslim menghadapi banyak kesulitan dalam memenuhi kebutuhan seharihari. Hal tersebut disebabkan oleh berbagai faktor di antaranya adalah; minimnya fasilitas tempat ibadah, sulitnya mencari makanan halal, adanya diskriminasi dalam pendidikan dan lain sebagainya. Sebagai contoh diskriminasi pendidikan di tambon Rattaphum. Untuk sekolah dasar dari 7 sekolah dasar 1 diantaranya sekolah yang muslim. Sedangkan untuk jenjang pendidikan menengah tidak ada yang khusus muslim. Di Sekolah menengah Rattaphum Wittaya sebenarnya mengizinkan untuk masyarakat yang beragama Islam melanjutkan pendidikan di sekolah Buddha, namun mereka yang beragama Islam harus menyesuaikan diri dengan ajaran-ajaran Buddha. Seperti berdoa, makan, dan bagi yang perempuan tidak diperbolehkan untuk memakai hijab. Selain itu, kebutuhan primer yakni makanan dan minuman halal juga sulit diperoleh. Banyak sekali kedai makanan menjual makanan yang di dalamnya terdapat kandungan babi atau minyak babi. Di Thailand, minuman-minuman beralkohol bebas diperjualbelikan. Oleh sebab itu, masyarakat yang beragama muslim harus tinggal secara berkelompok agar mendapatkan kemudahan terutama untuk menyokong kehidupan beragama.

Kesulitan-kesulitan yang dihadapi oleh minoritas muslim ini tentunya berpengaruh pada tiap kepala keluarga terutama dalam mengasuh anaknya agar senantiasa memeluk agama Islam dan beribadah sesuai dengan ajarannya. Menurut Ki Hajar Dewantara dalam Pertiwi (2014:20), "Peranan orangtua asuh merupakan lingkungan pertama yang dikenal oleh anak dalam hidupnya dan menjadi tempat tumbuh kembang untuk menjadi dewasa yang ditandai oleh tempat-tempat tinggal bersama, kerjasama ekonomi dan social". Berbagai macam pola asuh diterapkan untuk mendidik anak-anak mereka sesuai dengan kepribadian dan sikap orangtua.

Pola asuh dapat dikatakan sebagai pola pendekatan dan interaksi orangtua dengan anak dalam pengelolaan pendidikan di dalam keluarga. Menurut Dagun (2002:27), "Pola asuh merupakan interaksi anak dan orangtua mendidik, membimbing dan mendisplinkan serta melindungi anak untuk mencapai kedewasaan sesuai dengan norma-norma yang ada di dalam masyarakat". Tiga macam pola asuh menurut Hurlack dalam Mansur (2009), yakni pola asuh otoriter, permisif dan demokratis. Pola asuh orangtua diterapkan dalam pemberian pendidikan kepada anak, salah satunya adalah pendidikan agama.

Pendidikan agama Islam menurut Nasution dalam Basire (2010) adalah pendidikan dasar yang diberikan kepada anak dengan menanamkan keimanan dan moral dalam konsep Islam ke dalam jiwa anak remaja. 
Menurut Nisak, Ekosiswoyo, \& Fakhruddin (2012) Nisak (2012) orangtua mempunyai kewajiban untuk mendidik anak agar anak mempunyai perilaku yang baik dengan menerapkan ajaran-ajaran agama sebagai pilar utama yang menjadi penyaring dari pengaruh perkembangan ilmu pengetahuan dan teknologi yang dapat mempengaruhi pertumbuhan psikologi anak dan hal itu harus dilaksanakan sedini mungkin pada anak.

Menurut Papalia, Old, \& Feldman (2008:535), "Masa remaja adalah masa transisi perkembangan antara masa kanak-kanak dan masa dewasa yang mengandung perubahan besar fisik, kognitif dan psikososial". Menurut Yusuf (2009:26), "Remaja merupakan tahapan perkembangan manusia setelah kanak-kanak. Menurut Hurlock dalam Al-Mighwar (2006) berdasarkan bentuk perkembangan dan pola perilaku yang tampak khas bagi usia-usia tertentu, manusia perlu adanya pembatasanpembatasan usia yang meliputi; prenatal, neonatus, kanak-kanak, remaja, dewasa, setengah baya dan tua.

Beberapa penelitian tentang pola asuh orangtua sudah banyak dilakukan. Namun penelitian tersebut membahas pola asuh secara umum dalam aktivitas anak sehari-hari. Penelitian ini memfokuskan pola asuh orang tua dalam memberikan pendidikan agama kepada remaja keluarga muslim minoritas di Thailand. Tujuan penelitian bermaksud mendeskripsikan pola asuh yang diterapkan orangtua dalam memberikan pendidikan agama pada anak remaja, upaya-upaya yang dilakukan orangtua dan kendala-kendala yang dihadapi orangtua dalam keluarga muslim minoritas.

\section{METODE}

Jenis penelitian ini adalah penelitian deskriptif dengan pendekatan kualitatif yang dilakukan di Kampung Muslim Ban Khlong To Amphoe Rattaphum Provinsi Songhkla Thailand. Bogdan \& Taylor dalam Moleong (2000) mendefinisikan metode kualitatif sebagai prosedur penelitian yang menghasilkan data deskriptif berupa kata-kata tertulis atau lisan dari orang-orang dan perilaku yang diamati. Teknik pengumpulan data pada penelitian ini menggunakan metode observasi, wawancara dan dokumentasi. Data yang diperoleh dilakukan pengujian keabsahannya dengan menggunakan teknik triangulasi metode dan sumber. Data dianalisis menggunakan teori Miles \& Hubberman dalam Sugiyono (2015) yakni meliputi pengumpulan data, reduksi data, penyajian data dan kesimpulan. Subjek penelitian adalah 2 orangtua dari keluarga yang berbeda sebagai informan utama. Peneliti juga mengambil 5 informan pendukung yakni anak dan orang-orang terdekat dari subjek penelitian.

\section{HASIL DAN PEMBAHASAN Pola Asuh Orangtua}

Berdasarkan penelitian yang dilakukan terhadap 2 keluarga muslim minoritas di Amphoe Rattaphum Songhkla Thailand didapatkan hasil bahwa dalam pola pengasuhan pada anak terdapat 3 jenis pola asuh yakni otoriter, demokratis dan permisif. Pola asuh orangtua memiliki tiga tipe atau gaya pengasuhan yang dapat diterapkan oleh orangtua, yakni permisif, otoriter dan demokratis. Seperti teori yang dikemukakan oleh Baumrind dalam Santrock (2007) berpendapat bahwa terdapat tiga pola atau gaya pengasuhan orangtua, yaitu gaya pengasuhan otoriter, demokratis dan permisif.

Pola pengasuhan yang diterapkan dalam dua keluarga muslim minoritas di Amphoe Rattaphum Provinsi Songhkla, Thailand dalam memberikan pendidikan agama Islam adalah pola asuh demokratis dan otoriter. Pola asuh permisif tidak digunakan, hal ini disebabkan oleh karakteristik dari pola asuh permisif yang bersifat membebaskan, sesuai dengan teori yang disampaikan oleh Bolson dalam Sonita (2013) bahwa pola asuh permisif yakni pola asuh dimana orangtua bertindak menghindari adanya konflik ketika orangtua merasa tidak berdaya untuk mempengaruhi anak. Akibatnya orangtua membiarkan perbuatan-perbuatan salah yang dilakukan anak. Dalam hal ini orangtua kurang dapat membimbing anak karena anak dibiarkan melakukan tindakan sesuka hati dan tidak ada kontrol dari orangtua. Namun dalam kaitannya 
dengan memberikan pendidikan agama kepada anak, orangtua cenderung menggunakan pola asuh demokratis dan otoriter di dalam keluarga. Hasil penelitian juga menunjukkan bahwa penggunaan pola asuh otoriter lebih dominan dibandingkan dengan pola asuh demokratis, hal tersebut ditunjukkan dengan banyaknya aspek ajaran-ajaran Islam yang diterapkan di rumah dengan menggunakan pola asuh otoriter.

Hasil penelitian menunjukkan bahwa dalam dua keluarga menggunakan pola asuh demokratis dan otoriter. Pola asuh tersebut digunakan berbeda-beda sesuai dengan aspekaspek atau unsur ajaran Islam tertentu. Pola asuh demokratis digunakan oleh Kak Iyat \& Kak Muna dalam memberikan pendidikan agama bagi anak mereka, khususnya dalam hal berpuasa, mencari ilmu, menjalin silaturahmi, akhlak kepada manusia dan akhlak kepada lingkungan. Sedangkan pola pengasuhan otoriter digunakan oleh Kak Iyat \& Kak Muna dalam dasar ajaran islam yakni terkait dengan syahadat, toharoh (bersuci), salat, membaca Alquran, membayar zakat, akhlak kepada Allah, makan dan minum halal. Jadi berdasarkan 14 pokok atau dasar ajaran Islam, 6 dasar Islam diajarkan di dalam keluarga dengan menggunakan pola asuh demokratis, dan 8 dasar Islam diajarkan di dalam keluarga dengan menggunakan pola asuh otoriter. Hal ini sesuai dengan teori yang dikemukakan oleh Santrock dalam Taganing \& Fortuna (2008) bahwa pola asuh authoritarian, yaitu pola asuh yang penuh pembatasan dan hukuman (kekerasan) dengan cara orangtua memaksakan kehendaknya, sehingga orangtua dengan pola asuh authoritarian memegang kendali penuh dalam mengontrol anak-anaknya.

Ciri-ciri dari pola asuh otoriter telah disampaikan oleh Hurlock dalam Taganing \& Fortuna (2008) yang mengemukakan ciri-ciri pola asuh, yaitu pola asuh otoriter mempunyai ciri; anak harus tunduk dan patuh pada kehendak orangtua, pengontrolan orangtua pada tingkah laku anak sangat ketat hampir tidak pernah memberi pujian, sering memberikan hukuman fisik jika terjadi kegagalan memenuhi standar yang telah ditetapkan orangtua, dan pengendalian tingkah laku melalui kontrol eksternal.

\section{Upaya yang Dilakukan Orangtua}

Data hasil wawancara dan observasi baik menggunakan metode dokumentasi maupun observasi dalam kehidupan kedua keluarga muslim minorits di Amphoe Rattaphum Provinsi Songhkla Thailand menunjukkan Mrs. Wanitcha \& Mrs.Muna melakukan berbagai upaya dalam menanamkan ajaran Islam kepada anak. Selama dua bulan bersama dua keluarga tersebut mendapati hasil bahwa dalam memberikan pendidikan agama didalam keluarga, orangtua melakukan upaya dengan empat metode. Adapun metode tersebut adalah metode storytelling yaitu dengan menceritakan pengalaman-pengalaman orangtua kepada anak, suri tauladan yaitu mencontoh perilaku Nabi Muhammad, pembelajaran langsung dengan mempraktikkan langsung kepada anak dan pemberian reward and punishment.

Berdasarkan penelitian yang dilakukan, didapati hasil bahwa dalam mengajarkan akhlak baik akhlak kepada manusia dan akhlak kepada lingkungan, orangtua menerapkan upaya dengan menjadikan pengalaman nabi sebagai suri tauladan. Hal ini karena anak memiliki kemampuan meniru khususnya ketika dalam masa remaja. Hal ini dapat dijelaskan dengan teori yang dikemukakan oleh Mahmud \& Muhammad (2005:235) bahwa, "Anak memiliki keistimewaan berupa kemampuan yang luar biasa untuk meniru, oleh sebab itu orang dewasa di sekitar anak harus dapat memberikan contoh yang baik bagi anak".

Pemberian pendidikan agama dalam hal keimanan dan haji, orangtua berupaya dengan memberikan cerita-cerita baik berasal dari pengalaman pribadi dan cerita-cerita dongeng religius. Hal ini sesuai dengan yang disampaikan Mahmud \& Muhammad (2005) dimana dalam storytelling orangtua menyajikan fakta-fakta objektif tentang prinsip-prinsip moral dengan menggunakan teori persuasi untuk anak-anak yang dapat berupa fakta sejarah, dongeng, ataupun pengalaman pribadi orangtua yang dapat dijadikan pembelajaran. 
Selanjutnya dalam mendidik anak pada hal toharoh, salat, puasa, zakat, mencari ilmu, menjalin silaturahmi, dan makan minum halal, kedua orangtua menerapkan upaya dengan cara pembelajaran langsung. Selanjutnya dalam pendidikan agama yakni sholat, membaca Alquran dan puasa, orangtua juga melakukan upaya dengan cara memberikan reward and punishment.

Didapatkan hasil bahwa pembelajaran secara langsung adalah upaya yang paling banyak digunakan oleh orangtua karena dari 14 pokok ajaran Islam 9 diantaranya dilakukan dengan upaya pembelajaran langsung. 3 di antaranya dilakukan dengan upaya suri tauladan, kemudian 2 dengan upaya storytelling, dan 3 lagi yang termasuk dalam upaya pembelajaran langsung yakni salat, membaca Alquran, dan puasa menggunakan juga upaya reward and punishment. Metode tersebut sesuai dengan yang diungkap oleh Mahmud \& Muhammad (2005) yaitu dalam menjadi suri tauladan yang baik, anak memiliki keistimewaan yaitu dapat meniru. Storytelling atau dongeng, menyajikan data-data atau objek nyata dengan cara yang menarik bagi anak dapat memberikan kemudahan bagi anak sehingga dapat memahami dan mengambil hikmah dari suatu peristiwa. Praktik pembelajaran langsung, yaitu dengan memberikan kesempatan pada anak untuk mempraktikkan sendiri prinsip-prinsip moral tertentu yang dipilihnya. Orangtua berperan sebagai pihak yang memberikan reinforcement baik positif maupun negatif terhadap prinsip yang digunakan oleh anak.

\section{Hambatan yang Dihadapi Orangtua}

Hambatan merupakan suatu faktor yang menyebabkan terkendalanya suatu hal. Berbicara mengenai hambatan pola asuh dalam keluarga muslim minoritas ini tentu tiap orangtua akan berbeda-beda. Namun berdasarkan penelitian kepada dua keluarga muslim minoritas di Thailand, yakni Mrs. Wanitcha \& Mrs. Muna bahwa hambatanhambatan dalam memberikan pendidikan agama kepada anak datang dari dalam lingkungan keluarga (intern) itu sendiri dan dari luar (ekstern) yakni lingkungan masyarakat.

Hasil dari wawancara dengan semua informan penelitian (baik informan utama maupun pendukung), didapatkan hasil bahwa kedua orangtua atau ibu yang memiliki anak dalam usia remaja di Amphoe Rattaphum Provinsi Songhkla Thailand, mereka menyatakan bahwa dalam memberikan pendidikan agama pada anak mereka, mereka menghadapi berbagai hambatan, baik yang bersifat internal maupun bersifat eksternal.

Hambatan orangtua yang bersifat internal dapat terlihat dari sebagian besar karakteristik dalam hambatan yang ditemui orangtua ketika memberikan pendidikan agama pada anak remaja, yang meliputi pendidikan aqidah yaitu dengan mendidik anak tentang keimanan, syahadat. Syariah meliputi toharoh, salat, puasa, zakat, haji, membaca Alquran, mencari ilmu, makan dan minum yang halal, menjalin silaturahmi. Akhlak meliputi akhlak kepada Allah, kepada sesama manusia dan kepada lingkungan. Adapun kendala eksternal yang dihadapi oleh orangtua berasal dari pengaruh luar yaitu lingkungan sekitar, baik lingkungan teman sepermainan maupun dalam lingkungan masyarakat. Teman sepermainan memberikan arti penting pengaruh pendidikan agama pada diri anak. Bahkan dapat saja bahwa pengaruh teman sebaya lebih besar daripada pengaruh orangtua. Demikian pula dengan lingkungan masyarakat dimana anak tersebut tinggal, juga memberikan pengaruh besar terhadap pendidikan agama bagi anak.

Pemberian pendidikan aqidah kepada anak, orangtua menghadapi beberapa hambatan yang muncul ketika proses mendidik agama Islam berlangsung. Hambatan yang paling banyak terjadi adalah hambatan yang berasal dari dalam lingkungan keluarga yakni hambatan internal. Khususnya hal ini disebabkan karena anak masih berada dalam tahapan usia remaja, dimana pada masa ini anak menjadi tidak realistis dan selalu mencari jawaban yang konkrit. Menurut Papalia, Old, \& Feldman (2008) masa remaja adalah masa transisi perkembangan antara masa kanak-kanak dan 
masa dewasa yang mengandung perubahan besar fisik dan, kognitif dan psikososial. Menurut Yusuf (2009:26), "Remaja merupakan tahapan perkembangan manusia setelah kanakkanak". Dimana pada masa ini, banyak menarik perhatian keluarga dan orang-orang di sekitar karena sifat-sifat khasnya dan peranannya yang menentukan kehidupan individu dalam masyarakat.

\section{SIMPULAN}

Kedua orangtua yang memiliki anak dalam usia remaja di Kampung Muslim Ban Khlong To Amphoe Rattaphum, Provinsi Songhkla Thailand menggunakan dua jenis pola asuh, yaitu demokratis dan otoriter. Pembelajaran secara langsung adalah upaya yang paling banyak digunakan oleh orangtua sebagai upaya memberikan pendidikan agama kepada anak. Upaya lainnya yaitu dengan menggunakan metode storytelling, suri tauladan, reward dan punishment. Adapun hambatan orangtua dalam memberikan pendidikan agama yang bersifat internal yaitu meliputi keimanan, toharoh, salat, berpuasa, dan membaca Alquran. Sedangkan hambatan eksternal adalah dalam keimanan, salat dan berpuasa.

Orangtua di Kampung Muslim Amphoe Rattaphum Provinsi Songhkla Thailand hendaknya membuat buku catatan ramadan dalam penekanan berpuasa pada anak supaya anak tidak terlalu tertekan. Dalam mengajarkan agama di dalam keluarga, komunitas masyarakat muslim baik tokoh masyarakat maupun tokoh agama yang bekerjasama dengan pemerintah lokal sebaiknya mengadakan sosialisasi, khususnya mengenai upaya-upaya yang seharusnya dilakukan orangtua dalam memberikan pendidikan agama kepada anak. Sekaligus orangtua senantiasa memberikan bimbingan-bimbingan kepada anak melalui konseling agama dan motivasi-motivasi agar anak senantiasa memiliki kepercayaan diri, kesadaran serta keyakinan yang kuat sebagai seorang muslim dalam menjalankan syariatsyariat agama.

\section{DAFTAR PUSTAKA}

Al-Mighwar, M. (2006). Psikologi remaja: Petunjuk bagi guru dan orangtua. Bandung: Pustaka Setia.

Aphornsuvan, T. (2003). History and politics of the muslim in thailand. Thailand: Thammasat University.

Basire, J. H. T. (2010). Urgensi pendidikan agama dalam keluarga terhadap pembentukan kepribadian anak. HUNAFA: Jurnal Studia Islamika, 7(2), $163-178$.

Dagun, S. (2002). Psikologi keluarga. Yogyakarta: Pustaka Pelajar.

Mahmud, M. A. J., \& Muhammad, A. H. K. (2005). Membangun keluarga qurani: Panduan untuk wanita muslimah. Jakarta: Amzah.

Mansur, M. (2009). Pendidikan anak usia dini dalam islam. Yogyakarta: Pustaka Pelajar.

Moleong, L. J. (2000). Metodologi penelitian kualitatif. Bandung: Remaja Rosdakarya.

Nisak, H. K., Ekosiswoyo, R., \& Fakhruddin, F. (2012). Pola asuh orangtua dalam menanamkan kedisiplinan anak (Studi kasus pada keluarga buruh pabrik di kelurahan patemon kecamatan gunungpati kota semarang). Journal of Nonformal Education and Community Empowerment, 1(1), 32-40.

Papalia, D. E., Old, S. W., \& Feldman, R. D. (2008). Human development (psikologi perkembangan) (edisi kese). Jakarta: Kencana Prenada Media Group.

Pertiwi, S. (2014). Pola pengasuhan untuk pengembangkan karakter anak (Studi kasus di yayasan tunas rajawali kota semarang). Journal of Nonformal Education and Community Empowerment2, 3(1), 17-29.

Santrock, W. J. (2007). Perkembangan anak (Edisi Kese). Jakarta: Erlangga.

Sonita, S. (2013). Hubungan antara pola asuh orangtua dengan disiplin siswa di sekolah. Jurnal Profesi Konseling, 2(1), 174-181.

Sugiyono, S. (2015). Memahami penelitian kualitatif. Bandung: Alfabeta.

Taganing, N. M., \& Fortuna, F. (2008). Hubungan pola asuh otoriter dengan perilaku agresif pada remaja. Depok: Fakultas Psikologi Universitas Gunadarma.

Yusuf, I. (2003). Religious diversity in a buddhist mayority country. Thailand: International Association for Buddhist \& Culture.

Yusuf, S. (2009). Psikologi perkembangan anak dan remaja. Bandung: Remaja Rosdakarya. 